\title{
PENGARUH ECONOMIC VALUE ADDED DAN INVESMENT OPPORTUNITY SET TERHADAP KEBIJAKAN DIVIDEN (Studi Kasus pada Sektor Jasa yang Terdaftar di Bursa Efek Indonesia Periode 2013-2017)
}

\author{
Zumrotul Khasanah ${ }^{1}$ Abdul Salam.,M.M² Lukman Hakim.,M.Si ${ }^{2}$
}

${ }^{1}$ Program Studi Manajemen, Fakultas Ekonomi dan Bisnis Universitas Teknologi ABSTRAK Sumbawa

*) e- mail: khanahasana1996@gmail.com

Penelitian ini bertujuan untuk mengetahui: 1) Pengaruh dari Economic Value Added terhadap Kebijakan Dividen pada Sektor Jasa yang Terdaftar di Bursa Efek Indonesia Periode 2013-2017. 2) Pengaruh Invesment Opportunity Set terhadap Kebijakan Dividen pada Sektor Jasa yang Terdaftar di Bursa Efek Indonesia Periode 2013-2017. Model yang digunakan dalam analisis data adalah regresi linear berganda data panel. Alat analisis yang digunakan dalam penelitian ini adalah EViews 9. Data yang digunakan yaitu data sekunder dengan pengambilan sampel secara purposive sampling. Hasil Penelitian menunjukkan bahwa 1) Economic Value Added (EVA) berpengaruh positif dan signifikan yang ditunjukkan dengan nilai probabilitas untuk variabel EVA ialah sebesar 0.004 dimana nilai ini $<0.05$. 2) Invesment Opportunity Set (IOS) berpengaruh positif signifikan yang ditunjukkan dengan nilai probabilitas untuk variabel IOS ialah $0.010<$ alpha 0.05 . Secara simultan EVA dan IOS mempengaruhi DPR sebesar 69.4\%.

Kata kunci: Economic Value Added, Invesment Opportunity Set dan Kebijakan Dividen, Sektor Jasa.

\section{Pendahuluan}

Pada era globalisasi seperti ini persaingan bisnis begitu ketat dan signifikan sehingga para manajer harus berhati-hati dalam mengambil tindakan yang efektif ataupun efesien dalam pengelolaan suatu perusahaan. Mengelola sebuah perusahaan pasti dibutuhkan dana yang dimana dana tersebut berasal dari internal yang dimiliki perusahaan dan dana eksternal yang dimiliki investor. Investor lebih tertarik berinvestasi pada perusahaan yang mempunyai kebijakan dividen relatif stabil atau cenderung naik, karena hal tersebut investor beranggapan jika berinvestasi pada kebijakan dividen yang stabil maka akan lebih terjamin pengembalian keuntungannya. Selain itu, berdasarkan bird in hand theory investor lebih menyukai pendapatan yang diharapkan dari pembagian dividen daripada capital gain, mengingat investor menilai lebih tinggi dividen yang diterima sekarang dibandingkan dengan capital gain yang diterima di masa mendatang (Faus dan Rosidi, 2017).

Berdasarkan signaling theory suatu kenaikan dividen merupakan suatu sinyal kepada para investor bahwa manajemen perusahaan meramalkan suatu pengahasilan yang baik di masa mendatang. Selain itu kebijakan dividen penting karena dapat mengurangi konflik keagenan antara manajer dengan pemegang saham. Sebagai contoh, manajer disewa oleh pemegang saham untuk menjalankan perusahaan agar tujuan pemegang saham (maksimisasi kemakmuran pemegang saham) bisa tercapai. Tetapi manager bisa mempunyai agenda sendiri yang tidak selalu konsisten dengan tujuan pemegang saham. Misalkan perusahaan mempunyai kelebihan kas atas proyek dengan NPV positif. Kas tersebut akan lebih baik jika dibagikan kepada pemegang saham, tetapi manager barangkali tidak mau membagi kas tersebut karena ingin tetap memegang kendali atas kas tersebut. Dalam konteks seperti ini pembayaran dividen merupakan hal yang diinginkan oleh investor karena akan mengurangi konflik antara manager dengan pemegang saham (Hanafi, 2014:367).

Peneliti menggunakan economic value added (EVA) sebagai salah satu faktor yang mempengaruhi kebijakan dividen karena dengan metode EVA perusahaan dapat mengutamakan perhatiannya kepada hasil nilai perusahaan dimana dapat memasukkan konsep biaya modal (cost of capital) yang menilai perusahaan secara adil dalam artian bahwa perhitungan EVA mempertimbangkan kepentingan 
pemegang saham maupun investor di samping kepentingan perusahaan itu sendiri. Biaya modal mencerminkan kompensasi atau return yang diharapkaninvestor atas sejumlah investasi yang ditanamkan perusahaan. Secara eksplisit mempertimbangkan risiko yang dihadapi perusahaan yang diharapkan oleh para investor. EVA positif menandakan bahwa perusahaan mampu memperoleh laba melebihi biaya modalnya. Secara ekonomis perusahaan mampu membayar kewajiban keuangannya serta mampu mendistribusikan keuntungan atau dividen kepada pemegang saham. EVA dapat disimpulkan sebagai pengukuran kinerja keuangan perusahaan yang mampu mengungkap unsur biaya modal (Kusumawati dan Hamidah, 2017).

Peneliti menggunakan investment opportunity set (IOS) sebagai salah satu faktor yang mempengaruhi kebijakan dividen dimana menurut Hanafi (2014:375) salah satu faktor yang perlu dipertimbangkan dalam kebijakan dividen adalah kesempatan investasi. IOS secara umum menggambarkan tentang luasnya kesempatan atau peluang investasi bagi suatu perusahaan, namun sangat tergantung pada pilihan pembiayaan perusahaan untuk kepentingan dimasa yang akan datang. Berdasarkan penelitian Haryetti dan Ekayanti (2017) jika kondisi suatu perusahaan mengalami pertumbuhan lambat maka akan cenderung membagikan dividen lebih tinggi untuk mengatasi masalah overinvestment. Perusahaan yang mengalami pertumbuhan lambat atau pada saat kondisi perekonomian kurang baik untuk melakukan investasi baru ataupun proses reinvestasi, perusahaan akan cenderung membagikan dividen lebih tinggi untuk menarik minat pemegang saham agar terus menanamkan sahamnya pada perusahaan tersebut (Mardaleyani dan Wiksuana, 2015).

\section{TINJAUAN PUSTAKA}

\section{Economic Value Added}

Economic value added (EVA) menurut Brigham dan Houston (2010:111) adalah nilai yang ditambahkan oleh manajemen kepada pemegang saham selama satu tahun tertentu. EVA mencerminkan laba residu yang tersisa setelah biaya dari seluruh modal termasuk modal ekuitas dikurangkan. EVA dapat dihitung sebagai berikut:

$$
\mathrm{EVA}=\mathrm{NOPAT}-(\text { WACC } x \text { Invested Capital })
$$

\section{Invesment Opportunity Set}

Menurut Sunariyah (2009:56) IOS adalah kombinasi antara aktiva yang dimiliki perusahaan (assets in place) dan pemilihan investasi pada masa yang akan datang dengan net present value (NPV) yang positif. IOS dapat dihitung dengan rumus:

MVA/BVA = Total aktiva - total equitas + (jumlah saham beredar x closing price) / total aktiva

\section{Dividen}

Halim (2015:135) mengatakan bahwa dividen adalah alat penduga mengenai prestasi perusahaan dimasa mendatang, dividen menyampaikan pengharapan-pengharapan manajemen mengenai masa depan. Syakur (2015:201) mengatakan bahwa dividen merupakan bagian dari laba ditahan perusahaan yang dibagikan kepada pemegang saham sebagai keuntungan investasi.

\section{Teori Kebijakan Dividen}

\section{1) Bird in the Hand Theory}

Myron Gordon dan John Lintner berpendapat kebijakan dividen berpengaruh positif terhadap harga pasar saham. Artinya, jika dividen yang dibagikan perusahaan semakin besar, harga pasar saham perusahaan tersebut akan semakin tinggi dan sebaliknya. Investor lebih merasa aman untuk memperoleh pendapatan berupa pembayaran dividen daripada menunggu capital gain. Hal ini terjadi karena pembagian dividen dapat mengurangi ketidakpastian yang dihadapi investor (Sartono, 2012:282).

\section{2) Signaling Theory}

Teori ini MM berpendapat bahwa suatu kenaikan dividen yang di atas kenaikan normal biasanya merupakan suatu sinyal kepada para investor bahwa manajemen perusahaan meramalkan suatu penghasilan yang baik di masa yang akan datang. Sehingga dikatakan kenaikan harga setelah adanya kenaikan dividen semata-mata disebabkan oleh efek sinyal atau mungkin preferensi investor terhadap dividen (Sartono, 2012:284).

\section{3) Free Cash Flow Theory}

Free cash flow adalah cash flow yang tersedia untuk dibagikan kepada para investor setelah perusahaan melakukan investasi pada fixed asset dan working capital yang diperlukan untuk mempertahankan kelangsungan hidup perusahaan (Sartono, 2012:121).

\section{Dividend Payout Ratio (DPR)}

Menurut Murhadi (2013:65) DPR merupakan rasio yang menggambarkan besarnya proporsi dividen yang dibagikan terhadap pendapatan bersih perusahaan. Kemudian menurut Hanafi dan Halim (2009:86) mengatakan bahwa DPR merupakan rasio pembayaran dividen yang melihat bagian earning (pendapatan) yang dibayarkan sebagai dividen kepada investor. DPR dapat dihitung dengan rumus:

\section{$\mathrm{DPR}=$ Dividend per share/earning per share}

\section{KERANGKA KONSEPTUAL DAN HIPOTESIS PENELITIAN}

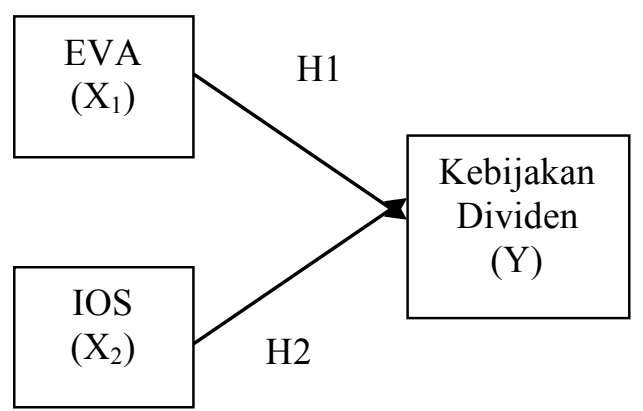


Keterangan :

$\mathrm{X} 1=$ Economic Value Added

$\mathrm{X} 2$ = Invesment Opportunity Set

$\mathrm{Y}=$ Kebijakan Dividen

\section{HIPOTESIS}

$\mathrm{H}_{1}$ : Economic value added berpengaruh signifikan terhadap kebijakan dividen.

$\mathrm{H}_{2}$ : Invesment opportunity set berpengaruh signifikan terhadap kebijakan dividen.

\section{METODE PENELITIAN}

Penelitian ini merupakan penelitian yang menggunakan pendekatan metode kuantitatif. Desain penelitian ini merupakan penelitian kausal, yaitu penelitian yang mencari keterkaitan sebab-akibat dari sebuah masalah (Chang, 2014:123). Populasi dalam penelitian ini yaitu kelompok sektor ketiga atau sektor jasa yang terdaftar di Bursa Efek Indonesia (BEI) selama periode 2013-2017. Sampel dari penelitian ini adalah perusahaan jasa yang terdaftar di Bursa Efek Indonesia (BEI) selama periode 2013-2017. Metode penentuan sampel yang digunakan adalah purposive sampling yang dipiih berdasarkan kriteria-kriteria tertentu.

\section{Teknik Analisis Data}

Metode analisis yang digunakan dalam penelitian ini adalah regresi linear berganda data panel. Teknik analisis data dalam penelitian ini adalah dengan menggunakan uji asumsi klasik, dan uji hipotesis. Pada regresi data panel dengan model FEM asumsi klasik yang harus terpenuhi adalah heteroskedastisitas dan multikolonearitas, (Gujarati, 2004:112-113). Interpretasi hasil penelitian baik secara parsial melalui uji-t maupun secara simultan melalui uji-F. Alat analisis yang digunakan Eviews 9.

\section{HASIL DAN PEMBAHASAN}

\section{Hasil Uji Asumsi Klasik}

\section{Uji Normalitas}

Berdasarkan uji normalitas dapat diketahui bahwa nilai Jarque-bera sebesar 272.15 dan nilai probabilitas 0.0000 berarti lebih kecil dari $\alpha=0,05$, yang berarti data dalam penelitian ini tidak berdistribusi dengan normal.

\section{Uji Multikolonieritas}

Berdasarkan Tabel 2, di atas diperoleh nilai correlation EVA-IOS sebesar $0.011<0.8$, maka dapat disimpulkan tidak terdapat multikolonieritas.

\section{Uji Autokorelasi}

Berdasarkan nilai Durbin Watson statistic dapat diketahui bahwa 4-dU $\leq \mathrm{d} \leq 4$-dL maka tidak dapat mengambil kesimpulan apapun.

\section{Uji Heterokedastisitas}

Berdasarkan hasil uji Glejser di peroleh nilai probabilitas sebesar $0.0732>$ alpha 0.05 , maka dapat disimpulkan tidak terjadi heterokedastisitas.

\section{Hasil Uji Pemilihan Model}

\section{Hasil Uji Chow}

Hasil uji chow menunjukkan nilai probabilitas $0.0000 \leq$ nilai alpha 0,05 . sehingga $\mathrm{H}_{0}$ ditolak dan $\mathrm{H}_{1}$ diterima, artinya model fixed effect yang tepat digunakan dibandingkan dengan common effect untuk mengestimasi data panel.

\section{Hasil Uji Hausman}

Berdasarkan hasil uji hausman pada Tabel 4.2.2 di atas, dapat dilihat bahwa nilai probabilitas $0.0030 \leq$ alpha 0.05 sehingga $\mathrm{H}_{0}$ ditolak dan $\mathrm{H}_{1}$ diterima artinya model fixed effect lebih baik dari pada model random effect.

\section{Uji Hipotesis}

Analisis regresi linier berganda data panel pada penelitian ini menggunakan metode fixed effect. Pengujian ini dilakukan dengan tingkat signifikansi sebesar $\alpha=0,05$ (5\%). Pengujian model regresi secara parsial dilakukan dengan uji t, sedangkan pengujian model regresi secara simultan dilakukan dengan menggunakan Uji F.

1. Uji t (Uji Parsial)

Hipotesis 1: EVA berpengaruh signifikan terhadap kebijakan dividen.

Berdasarkan hasil penelitian menggunakan model fixed effect dapat diketahui besarnya nilai probabilitas untuk variabel EVA ialah sebesar 0.004 dimana nilai ini $\leq$ 0.05. Dengan demikian EVA berpengaruh signifikan terhadap DPR dengan koefisien sebesar 1.10 yang berarti setiap ada peningkatan variabel EVA sebesar satu satuan maka akan meningkatkan DPR sebesar 1.10.

Hipotesis 2: IOS berpengaruh signifikan terhadap kebijakan dividen.

Berdasarkan hasil penelitian menggunakan model fixed effect dapat diketahui besarnya nilai probabilitas untuk variabel IOS ialah sebesar 0.010 di mana nilai ini $<$ 0.05. Berdasarkan tingkat kepercayaan $95 \%$, dapat ditarik kesimpulan bahwa $\mathrm{H}_{1}$ diteriima. Dengan demikian IOS berpengaruh signifikan terhadap DPR dengan koefisien beta sebesar 0.120 yang berarti setiap ada peningkatan variabel IOS sebesar satu satuan maka akan meningkatkan DPR sebesar 0.120.

\section{Uji F (Uji Simultan)}

Berdasarkan hasil penelitian dengan model fixed effect diperoleh probabilitas F-hitung sebesar $0.000 \leq 0.05$, dengan tingkat kepercayaan 95\%. Maka dapat di simpulkan bahwa terdapat pengaruh signifikan EVA dan IOS secara bersama-sama terhadap DPR.

\section{Koefisien Determinasi}

Hasil pengujian dengan model fixed effect pada Tabel 4.4, dapat diketahui besarnya nilai $R$-Square yaitu 0.694 yang berarti bahwa DPR dapat dijelaskan oleh variabel EVA dan IOS sebesar 0.694 atau sebesar 69.4\% 
sedangkan sisanya sebesar $30.6 \%$ dijelaskan oleh faktor-faktor lain yang tidak terdapat dalam penelitian ini misalnya:

\section{PEMBAHASAN}

1. Pengaruh economic value added terhadap kebijakan dividen

EVA berpengaruh positif signifikan terhadap DPR menunjukkan bahwa kinerja perusahaan yang diukur melalui nilai tambah ekonomis dapat memengaruhi kebijakan dividen. Nilai EVA yang positif menunjukkan bahwa perusahaan berhasil menciptakan nilai bagi pemilik modal karena perusahaan mampu menghasilkan laba bersih melebihi biaya modal yang ditanamkan. Artinya secara ekonomis perusahaan mampu melunasi kewajiban keuangannya dan mampu membagikan dividen kepada pemegang saham. Semakin tinggi laba bersih yang diperoleh perusahaan maka semakin tinggi nilai aset perusahaan. Semakin tinggi aset yang dimiliki perusahaan maka dividen yang dibagikan kepada pemegang saham juga semakin tinggi.

Berdasarkan signaling theory yang suatu kenaikan dividen merupakan suatu sinyal kepada investor bahwa perusahaan mampu memperoleh penghasilan yang baik dan mempunyai prospek yang bagus di masa mendatang sehingga investor menaruh kepercayaan yang tinggi dan kemudian tertarik untuk berinvestasi pada perusahaan (Sartono, 2012:284).

EVA tidak hanya mempertimbangkan kepentingan para pemegang saham namun EVA juga mempertimbangkan kepentingan perusahaan dimana EVA yang positif membantu perusahaan mengeliminasi aktivitas atau proses yang tidak menambah nilai dan dapat membantu memastikan bahwa

manajemen telah menjalankan operasi dengan cara konsisten yang menghasilkan nilai tambah ekonomis bagi perusahaan untuk digunakan sebagai kegiatan maupun strategi selama periode tertentu sehingga menjadi cara untuk menilai kinerja keuangan perusahaan.

2. Pengaruh invesment opportunity set (IOS) terhadap kebijakan dividen

IOS berpengaruh positif signifikan terhadap DPR menunjukkan bahwa perusahaan yang memiliki kesempatan investasi yang tinggi dapat meningkatkan pembayaran dividen. Semakin tinggi perputaran aset yang digunakan oleh perusahaan untuk berinvestasi, maka semakin besar laba bersih yang diperoleh perusahaan. Semakin besar laba bersih yang diperoleh perusahaan maka semakin tinggi aset yang dimiliki perusaha. Semakin tinggi aset maka dividen yang dibagikan perusahaan kepada pemegang saham akan semakin tinggi.

Berdasarkan free cash flow theory, cash flow yang tersedia dibagikan kepada pemegang saham setelah perusahaan melakukan investasi pada fixed asset dan working capital yang diperlukan untuk mempertahankan kelangsungan usahanya (Sartono, 2012:121). Free cash flow sebagai aliran kas yang tersisa setelah semua proyek dengan NPV yang positif didanai. Free cash flow lebih baik dibagikan kepada pemegang saham dan bukan ditahan, dikarenakan perusahaan sudah tidak mempunyai kesempatan investasi yang menguntungkan. Kemudian pemegang saham dapat memanfaatkan kas yang diterima tersebut agar bisa memaksimumkan kemakmurannya (Hanafi, 2014:12).

\section{KESIMPULAN}

EVA berpengaruh positif signifikan terhadap pembayaran dividen. Hal ini menunjukkan bahwa kinerja perusahaan yang diukur melalui nilai tambah ekonomi perusahaan mempegaruhi pembayaran dividen perusahaan. Semakin besar nilai tambah ekonomi atau EVA perusahaan, maka semakin baik kinerja perusahaan. Semakin baik kinerja perusahaan, maka semakin besarnya dividen yang dibagikan kepada pemegang saham. Semakin besar dividen yang dibagikan, maka berdasarkan signaling theory suatu kenaikan dividen dapat memberikan sinyal kepada investor bahwa perusahaan mampu memperoleh penghasilan yang baik. Sehingga investor merasa terjamin pengembalian (return) atas investasinya dan cenderung menambah investasinya. Semakin banyak investor yang menanamkan modal terhadap perusahaan, maka harga pasar saham semakin baik atau stabil

1. IOS berpengaruh positif pada kebijakan dividen perusahaan. Artinya, semakin tinggi tingkat kesempatan investasi maka dividen yang dibayarkan juga semakin meningkat. Berdasarkan free cash flow theory kas yang tersisa lebih baik dibagikan kepada pemegang saham dan bukan ditahan, dikarenakan perusahaan sudah tidak mempunyai kesempatan investasi yang menguntungkan. Kemudian pemegang saham dapat memanfaatkan kas yang diterima tersebut agar bisa memaksimumkan kemakmurannya.

\section{Saran}

\section{Bagi Perusahaan}

Dividen payout ratio merupakan variabel penting, oleh karena itu perusahaan harus senantiasa mampu mengendalikan besarnya DPR yang akan dibagikan kepada pemegang saham agar harga pasar saham dalam keadaan baik dan stabil.

\section{Bagi Investor}

Pertimbangan investor untuk menanamkan modalnya ke perusahaan dan menginginkan pembagian dividen yang jumlahnya relatif besar sebaiknya melihat nilai tambah ekonomi atau EVA dan IOS agar investor dapat memilih perusahaan mana yang akan dipilih untuk berinvestasi.

\section{Bagi Penelitian Selanjutnya}

Untuk peneliti-peneliti selanjutnya, dapat menambah variabel lain seperti profitabilitas, likuiditas, dan leverage agar dapat menjelaskan lebih lanjut mengenai faktor-faktor yang mempengaruhi kebijakan dividen. Serta dapat menambah time series agar mendapatkan hasil yang lebih baik. 


\section{DAFTAR PUSTAKA}

Anam, Arfan, dan Shabri. (2016). Pengaruh Profitabilitas dan Invesment Opportunity Set terhadap Kebijakan Dividen pada Perusahaan Manufaktur di Indonesia. Jurnal Magister Akuntansi, 5(3), 20-24.

Andaswari, Pitono dan Hardianto. (2017). Analisis Pengaruh Investment Opportunity Set terhadap Kebijakan Dividen serta Implikasinya terhadap Nilai Perusahaan Konstruksi yang Terdaftar di Bursa Efek Indonesia. Jurnal Manajemen dan Ekonomi Bisnis, 1(1), 498-491.

Anthony, Robert dan Govindarajan, Vijay. (2012). Manajemen Control System: Sistem Pengendalian Manajemen. Jakarta: Salemba Empat.

Brigham, Eugene dan Houston, Joel. (2010). Dasar-dasar Manajemen Keuangan: Essentials of Financial Management, 11th Edition Book 1. Jakarta: Salemba Empat.

Brigham, Eugene dan Houston, Joel. (2011). Dasar-dasar Manajemen Keuangan: Essentials of Financial Management, 11th Edition Book 2. Jakarta: Salemba Empat.

Chang, William. (2014). Metodologi Penulisan Ilmiah: Teknik Penulisan Esai, Skripsi, Tesis dan Disertai untuk Mahasiswa. Jakarta: Airlangga.

ERIA. (2019). Retrieved at 5 Maret 2019, From Website: www.eria.org

Faus, Achmad dan Rosidi. (2017). Pengaruh Aliran Kas, Kepemilikan Manajerial, Kepemilikan Institutional, Kebijakan Utang dan Colateral Aset Terhadap Kebijakan Dividen. Jurnal Ekonomi dan Manajemen, 8(2), 180-194.

Gaver, Jennifer dan Gaver, Kenneth. (1993). Additional Evidence on the Association Between the Invesment Opportunity Set and Corporate Financing, Dividend and Compensation Policies. Jurnal of Accounting and Economic, 16(1), 19160.

Ghozali, Imam. (2011). Aplikasi Analisis Multivariate Dengan Program SPSS. Semarang: Badan Penerbit Universitas Diponegoro.

Gujarati, Damodar. (2004). Basic Econometrics. United States: Gary Burke.

Halim, Abdul. (2015). Manajemen Keuangan Bisnis: Konsep dan Aplikasinya, Edisi pertama. Jakarta: Mitra Wacana Media.

Halim, Abdul dan Hanafi, Mamduh. (2009). Analisis Laporan Keuangan, Edisi Keempat. UPP STIM YKPN: Yogyakarta.

Hanafi, Mamduh. (2014). Manajemen Keuangan, Edisi Kesatu. Yogyakarta: BPFE.

IDX. (2019). Retrieved 5 Maret 2019, From Website: www.idx.co.id

Jogiyanto. (2012). Teori Portopolio dan Analisis Investasi, Edisi Ketujuh. Yogyakarta: BPFE.

Kallapur, Sanjay dan Mark Trombley. (2001). The Invesment Opportunity Set Determinants, Consequences and Measurement. Managerial Finance, 27(3), 3-15.

Kusumawati dan Hamidah. (2017). Economic Value Added (EVA) Sebagai Alat Ukur Kinerja Keuangan. Jurnal Akademika, 5(1), 7-9.

Kotler, Philip dan Keller, Kevin. (2013). Marketing Management, Jilid ke 2. Jakarta: Airlangga.

Mansuri. (2016). Praktikum Eviews: Analisis Regresi Linear Berganda Menggunakan Eviews. Jakarta: Universitas Borobudur.

Murhadi, Warner. (2013). Analisis Laporan Keuangan, Proyeksi dan Valuasi Saham. Jakarta: Salemba Empat.

Myers, S. C. (1977). Determinants of corporate borrowing. Journal of Financial Economics. Vol.5: 147-175.

Nachrowi, Nachrowi dan Usman Hardius. (2006). Pendekatan Popular dan Praktis Ekonometrika Untuk Analisis Ekonomi dan Keuangan. Jakarta: Fakultas Ekonomi Universitas Indonesia.

Nisfiannoor, Muhammad. (2013). Pendekatan Statistika Modern: Aplikasi dengan Software SPSS dan Eviews. Jakarta: Universitas Trisakti.

Riyanto, Bambang. (2010). Dasar-Dasar Pembelanjaan Perusahaan, Edisi keempat. Yogyakarta: BPFE Yogyakarta.

Sakti, Indra. (2018). Analisis Regresi Data Panel Menggunakan EViews. Jakarta: Universitas Esa Unggul.

Sartono, Agus. (2012). Manajemen Keuangan: Teori dan Praktik. Edisi keempat, Cetakan keenam. Yogyakarta: BPFE Yogyakarta.

Stanford.Education. (2019). Retrieved 5 Maret 2019, From Website: http://www.standford.edu

Sugiyono. (2010). Metode Penelitian Pendidikan Pendekatan Kuantitatif, Kualitatif, Dan $R \& D$. Bandung: Alfabeta.

Sunariyah. (2009). Pengantar Pengetahuan Pasar Modal. Yogyakarta: UPP AMP YKPN.

Sutrisno. (2012). Manajemen Keuangan Teori, Konsep dan Aplikasi, Edisi ke 8. Yogyakarta: Ekonisia.

Syakur, Ahmad Syafi'i. (2015). Intermediate Accounting. Jakarta: AV Publisher.

Tunggal, Amin. (2012). Memahami Konsep Economic Value Added (EVA) dan Value Based Management (VBM). Jakarta: Harvarindo.

Orlando, Zam Zam. (2018). Pengaruh Profitabilitas, 
Economic Value Added dan Pertumbuhan Aset terhadap Kebijakan Dividen (Studi Empiris pada Perusahaan Manufaktur yang Terdaftar di Bursa Efek Indonesia 2013-2017). Jurnal Ekonomi dan Bisnis, 2(4), 60-61.

Varanty, Mardaleyani dan Wiksuana, Bagus. (2015). Pengaruh Economic Value Added dan Invesment Opportunity Set terhadap Kebijakan Dividen. Jurnal Akuntansi, 2(12), 27-34.

Yusniar, Meina dan Sumarni, Indriarti. (2014). Pengaruh Invesment Opportunity Set terhadap Kebijakan Dividen. Jurnal Wawasan Manajemen, 2(2) 202-203. 
IFRI Vo1 n 4 Non nn 1 -6 
IFRI Vol n 4 No n) nn 1 _6 
IFRI Vol n 4 No $n$ ? nn 1 _6 
IFRI Vol n 4 Non $n$ nn 1 _6 
IFRI Vol n 4 No $n$ ? nn 1 _6 


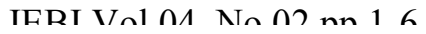


JEBI Vol. 04, No.01, pp. 1-8 